\title{
Integrating well log interpretations for lithofacies classification and permeability modeling through advanced machine learning algorithms
}

\author{
Watheq J. Al-Mudhafar ${ }^{1,2}$ (i)
}

Received: 20 December 2016/Accepted: 24 May 2017/Published online: 13 June 2017

(C) The Author(s) 2017. This article is an open access publication

\begin{abstract}
In this paper, an integrated procedure was adopted to obtain accurate lithofacies classification to be incorporated with well log interpretations for a precise core permeability modeling. Probabilistic neural networks (PNNs) were employed to model lithofacies sequences as a function of well logging data in order to predict discrete lithofacies distribution at missing intervals. Then, the generalized boosted regression model (GBM) was used as to build a nonlinear relationship between core permeability, well logging data, and lithofacies. The well log interpretations that were considered for lithofacies classification and permeability modeling are neutron porosity, shale volume, and water saturation as a function of depth; however, the measured discrete lithofacies types are sand, shaly sand, and shale. Accurate lithofacies classification was achieved by the PNN as the total percent correct of the predicted discrete lithofacies was $95.81 \%$. In GBM results, root-mean-square prediction error and adjusted $R$-square have incredible positive values, as there was an excellent matching between the measured and predicted core permeability. Additionally, the GBM model led to overcome the multicollinearity that was available between one pair of the predictors. The efficiency of boosted regression was demonstrated by the prediction matching of core permeability in comparison with the conventional multiple linear regression (MLR). GBM led to much more accurate permeability prediction than the MLR.
\end{abstract}

Watheq J. Al-Mudhafar

wmoham4@1su.edu

1 Louisiana State University, Patrick F. Taylor Hall, Baton Rouge, LA 70803, USA

2 Basra Oil Company, Basra, Iraq
Keywords Lithofacies classification - Permeability modeling $\cdot$ Probabilistic neural networks $\cdot$ Boosted regression $\cdot$ Well log interpretations

\section{Introduction}

Integration of rock facies classification into the formation permeability modeling, especially given the core measurement and well log interpretations, is a crucial step to reduce the uncertainty in reservoir characterization (Xu et al. 2012). Rock facies classification leads to improve the relationship between permeability and porosity and then results in efficiently estimating the petrophysical properties in noncored intervals (Lee and Datta-Gupta 1999). The discrete facies sequence is produced either from core measurements (lithofacies) or clustered from the well logging data (electrofacies) (Al-Mudhafar and Bondarenko 2015; Lee and Datta-Gupta 1999; Nashawi and Malallah 2009; Tang et al. 2004). The classification procedure starts with modeling the discrete facies distribution as a function of well logging data for limited intervals. Based on that modeling, the facies distribution is then predicted for the entire depth intervals for the well and other wells that have no facies measurements.

Many algorithms have been adopted for lithofacies/electrofacies classification, such as linear discriminant analysis (Al-Mudhafar 2014, 2015a, b; Lee and DattaGupta 1999; Rafik and Kamel 2016), multinomial logistic regression (Al-Mudhafar 2014; Tang et al. 2004), neural networks (Avseth and Mukerji 2002; Tang 2008; Wong et al. 1995), kernel support vector machine (Al-Mudhafar 2015a, b, 2017a, b), and principal component analysis (Adoghe et al. 2011). All these algorithms predict the discrete and continuous probability distributions of facies. 
In permeability modeling and prediction, there are many various algorithms that have been adopted to predict the permeability given core measurements and/or well logging records in addition to rock facies. These algorithms include multiple linear regression (Dahraj and Bhutto 2014; Mohaghegh et al. 1997; Xue et al. 1997), generalized additive modeling (Al-Mudhafar and Mohamed 2015; AlMudhafar and Bondarenko 2015; Lee et al. 2002; Rafik and Kamel 2016), multivariate adaptive regression splines (Al-Mudhafar and Al-Khazraji 2016; Xie 2008), neural networks (Lee and Datta-Gupta 1999; Lee et al. 2002; Mohaghegh et al. 1997), fuzzy logic (Nashawi and Malallah 2009), and support vector regression (Al-Anazi and Gates 2011).

In this paper, the probabilistic neural networks (PNNs) and generalized boosted regression model (GBM) were employed for lithofacies classification and core permeability estimation, respectively.

\section{Research methodology}

Linking between different reservoir parameters of distinct measurement scales is a complex procedure because the geological systems always have nonlinear behavior. Therefore, it is essential to consider nonlinear algorithms to model the response parameters, such as permeability or rock facies, as a function of independent variables (predictors), for instance well $\log$ interpretations. Since the predictors come from different sources with various scales of few inches, as in core measurements, and few feet, as in well logging data, it is important to look for the most efficient approach to model these different data sources. In this paper, we introduce an efficient workflow to integrate the probabilistic neural networks (PNNs), as a nonlinear facies classification algorithm, into the generalized boosted regression model (GBM), as nonlinear modeling algorithm, for core permeability modeling and prediction. To best of author's knowledge, the GBM algorithm has never been adopted before, at least in the literature of the petrophysical property modeling, to model the core permeability as a function of well logging and facies data.

PNN is an implementation of a statistical algorithm called Kernel discriminant analysis in which the operations are organized into a multi-layered feedforward network with four layers: input, pattern, summation, and output layers. GBM is a recent data mining technique that has shown considerable success in predictive accuracy as it maintains a monotonic relationship between the response and each predictor. In particular, PNN was employed to model lithofacies sequences in order to predict discrete lithofacies distribution for the entire reservoir thickness, including the missing intervals. After that, the predicted discrete facies distribution was included as a predictor in the multivariate permeability modeling through the GBM approach. The GBM was employed to build a nonlinear relationship between core permeability and well logging data conditioning to the lithofacies. More specifically, it was essential to model the permeability as a function of well logging data given each rock facies to estimate the core permeability in noncored intervals and other wells with preserving the reservoir heterogeneity. The well log interpretations of neutron porosity, shale volume, and water saturation along with the core measurements of permeability and lithofacies, were obtained for a well in the upper sandstone reservoir/Zubair formation in South Rumaila oil field, located in southern Iraq. The principle permeability model is illustrated in the following equation:

$y=f\left(x_{i}\right)+\epsilon_{i}$

where $x_{i}$ refers to the independent variables (predictors), $y$ is the expected core permeability, and $\epsilon_{i}$ is the residual.

To show the efficiency of the GBM algorithm, its performance was compared to the conventional multiple linear regression (MLR). The root-mean-square prediction error (RMSE) and adjusted $R$-square were considered as statistical validation tools to compare between MLR and GBM results. More specifically, the RMSE and $R_{\text {adj }}^{2}$ were considered to quantify the mismatch between the observed and predicted core permeability calculated by GBM and MLR. RMSE measures the expected squared difference between the observed and predicted core permeability, and $R_{\text {adj }}^{2}$ is the adjusted $R^{2}$ that explains the variance obtained by the permeability model adjusted for the number of predictors that improve the model:

$$
\begin{aligned}
& \mathrm{RMSE}=\sqrt{\frac{1}{n} \sum_{j=1}^{n}\left(\hat{f}_{j}\left(x_{i}\right)-f_{j}\left(x_{i}\right)\right)^{2}} \\
& R_{\mathrm{adj}}^{2}=1-\frac{\left(1-R^{2}\right)(n-1)}{n-k-1}
\end{aligned}
$$

where $R^{2}$ refers to the coefficient of determination in simple linear regression, or the coefficient of multiple determination in multiple linear regression, $n$ is the number of measurements and $k$ is the number of independent variables (predictors).

All the multivariate statistics analyses of lithofacies classification and permeability modeling with results visualizations were implemented through $R$, the most powerful open-source statistical computing language.

\section{Probabilistic neural network}

Specht (1990) has firstly introduced the probabilistic neural network (PNN) as an efficient nonlinear classification 
algorithm (Specht 1990). PNN is a type of supervised neural networks that are used in the pattern classification and recognition problems. This method was derived from the Bayesian network and a statistical algorithm called Kernel fisher discriminate analysis. In the PNN, the network is arranged into a multilayer feedforward network, which comprises of four different layers: input, pattern, summation, and decision/output. Figure 1 shows the interconnection between processing units or neurons of each of the four successive layers (Mao et al. 2000).

The PNN classifier was adopted in rock facies classification because it often learns more quickly than the other types of neural network classifiers, such as the back propagation network. In addition to the fast training process, PNN has other advantages in comparing with other neural networks like an inherently parallel structure. Training samples can also be added or removed without extensive retraining and guaranteed to converge to an optimal classifier as the size of the representative training set increases (Emary 2008). The entire procedure of facies classification in probabilistic neural network was implemented through pnn package (Chasset 2015) and doParallel package (Weston and Calaway 2015) in $R$ statistical language.

\section{Generalized boosted regression model}

Gradient boosting regression model (GBM) is a powerful machine learning tool derived by Friedman $(2001,2002)$ to capture complex nonlinear function dependencies. Generalized boosted regression is an implementation of expansion to Freund and Schapire's AdaBoost algorithm and J. Friedman's gradient boosting machine (Freund and Schapire 1997). GBM has been efficiently adopted in many data-driven tasks with high accuracy of modeling and prediction of response variables. In gradient boosting modeling, more accurate estimate of the response variable is obtained through consecutively fitting new models in order to reduce the variance between the predicted and observed responses. The main idea of GBM is to learn the data to achieve maximum correlation with the negative gradient of the loss function (Natekin and Knoll 2013). For continuous response, the loss function can be Gaussian or Laplace functions. However, binomial and AdaBoost loss functions are suitable for the categorical responses.

The main idea behind loss functions in GBM is to penalize large deviations from the target outputs along with neglecting small residuals. For continuous response variable, the appropriate loss function is the squared-error L2 loss and its derivative represents the residual. So, the GBM can be applied based on the residual fitting (Natekin and Knoll 2013). The GBM procedure begins with assigning a differentiable loss function, which represents the variance between observed and predicted response factor $y$ and starts with an initial model $F$, which can be averaging of $y$. Then, iteration is implemented until converge in order to next calculate negative gradients:

$-g\left(x_{i}\right)=-\frac{\partial L\left(y_{i}, F\left(x_{i}\right)\right)}{\partial F\left(x_{i}\right)}$.

The regression tree $h$ is later fitted to the negative gradients $-g\left(x_{i}\right)$. In this paper, the entire procedure of Gradient boosting regression modeling was implemented by $\mathrm{gbm}$ package in $R$, the most powerful open-source statistical language (Ridgeway 2017).

\section{Reservoir and data description}

In this paper, the well logging and core data were obtained for a well in the upper sandstone member in Zubair formation/South Rumaila oil field, located in southern Iraq. The giant South Rumaila oil field composed of many oilproducing reservoirs. Zubair formation is one of the oil reservoirs that is represented by Late Berriasian-Albian cycle and its sediments, which belongs to Lower
Fig. 1 General architecture of probabilistic neural networks (PNNs) (Mao et al. 2000)

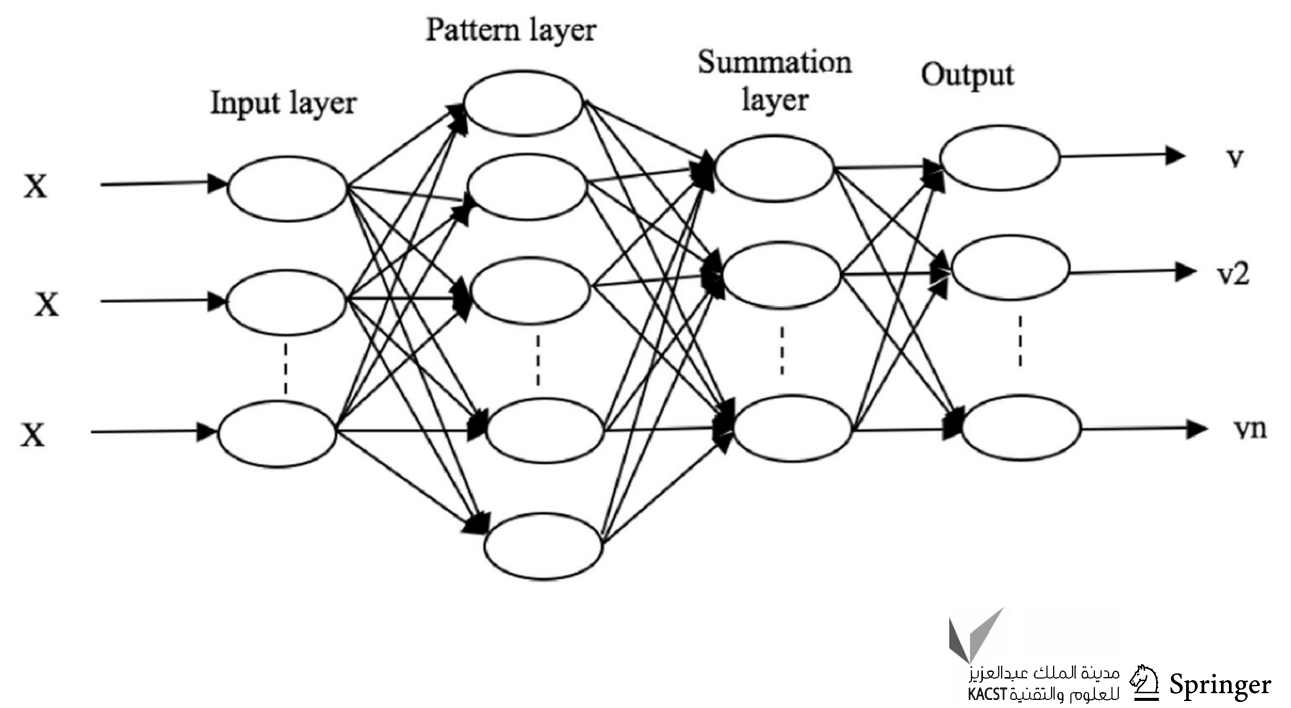


Cretaceous age (Al-Mudhafar 2017a, b). The Zubair formation of 280-400 m thickness range encompasses five members from top to bottom: upper shale member, upper sandstone member, middle shale member, lower sand member, and lower shale member. The upper sandstone member is the main pay zone of South Rumaila oil field (Mohammed et al. 2010). The main pay comprises five dominated sandstone units, separated by two shale units. The shale units act as good barriers impeding vertical migration of the reservoir fluids except in certain areas where they disappear. The five unit zones have been denoted from top to bottom as AB, DJ1, DJ2, LN1, and $\mathrm{LN} 2$, and there are two shale layers $\mathrm{C}$ and $\mathrm{K}$ between $\mathrm{AB}$ and DJ1 and DJ2 and LN1, respectively (Al-Ansari 1993). Figure 2 illustrates the geological column of lithology description in a well in South Rumaila oil field.
The well log interpretations were considered for lithofacies classification and permeability modeling. The well $\log$ interpretations include neutron porosity, shale volume, and water saturation, all as a function of reservoir depth. In addition, the measured discrete lithofacies types, which were obtained from core measurements, include sand, shaly sand, and shale. Figure 3 decorates the depth-based measured lithofacies and well log interpretations.

The total number of measurements in the dataset is 669 . Each reading represents the measured property in half-foot interval in the reservoir depth. The summary of the entire dataset is illustrated in Table 1.

Prior to implementing the permeability modeling, it was necessary to set up the cross-validation. The data were sampled and split into two parts: training with $75 \%$ and testing with $25 \%$. The modeling was conducted
Fig. 2 Geological lithology column of the formations in South Rumaila oil field (Modified from Al-Ameri et al. 2009 and Mohammed et al. 2010)

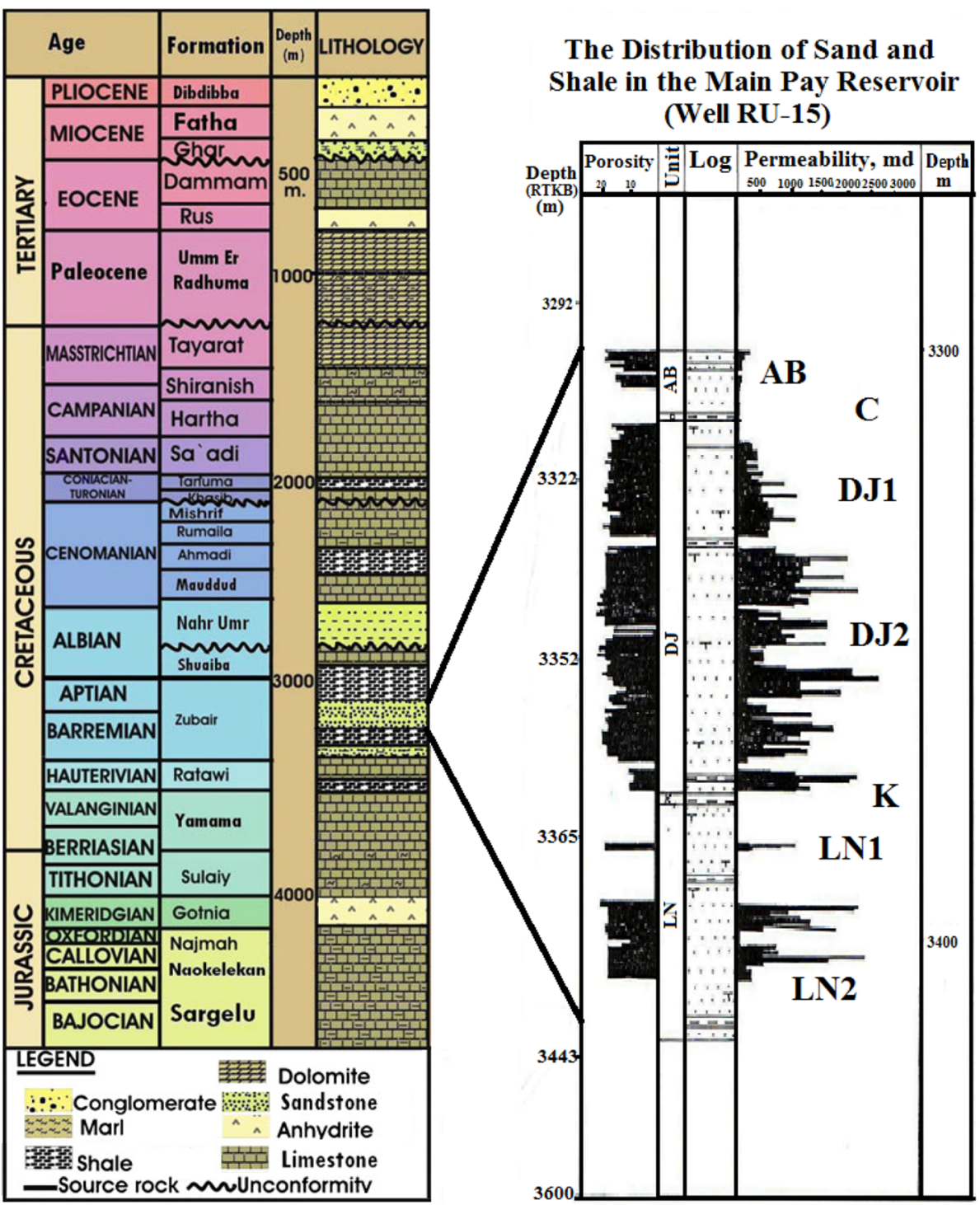


Fig. 3 Distribution of discrete lithofacies and well log interpretations. The measured lithofacies from core data analyses include sand, shale, and shaly sand only. The available well $\log$ interpretations are neutron porosity, shale volume, and water saturation
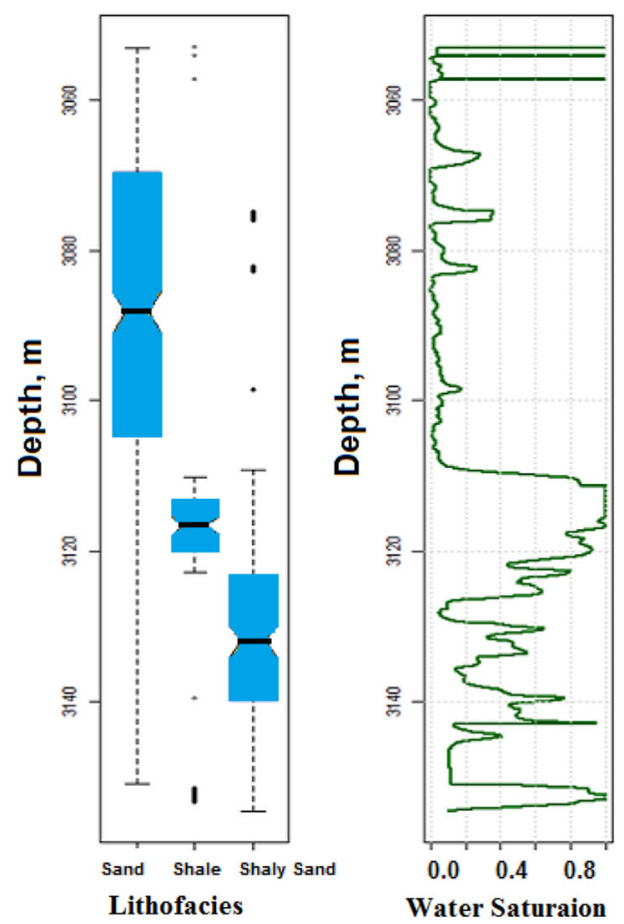

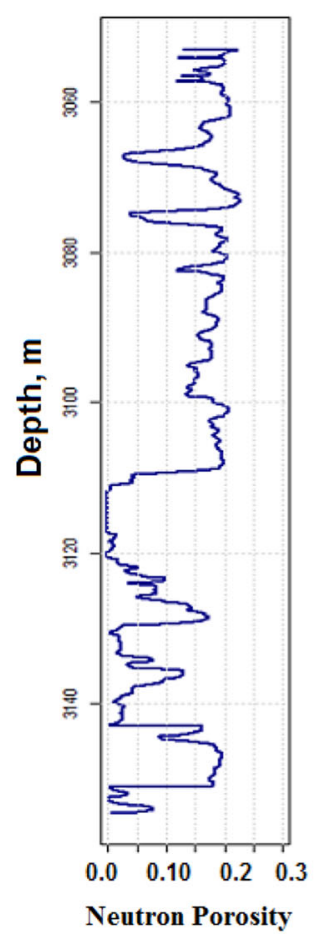

Table 1 Summary of well log interpretations and core-based discrete lithofacies distribution for the well under study

\begin{tabular}{llllll}
\hline Quantity & Depth & Sw & PhiN & Vsh & Lithofacies \\
\hline Min & 3053 & 0.00 & 0.00 & 0.00 & Sand: 417 \\
1st qu. & 3078 & 0.03225 & 0.05548 & 3.225 & Shale: 97 \\
Median & 3104 & 0.10174 & 0.15908 & 8.891 & Shaly sand: 155 \\
Mean & 3104 & 0.26551 & 0.12586 & 26.870 & \\
3rd qu. & 3129 & 0.45463 & 0.18674 & 45.463 & 100.000 \\
Max. & 3155 & 1.00000 & 0.22654 & & \\
\hline
\end{tabular}

based on the training subset, and prediction was adopted as a function of the testing subset. That led to provide more trust about the external prediction of the models. Table 2 shows the head of the sampled training subset data, while Table 3 shows the head of the sampled testing subset data.

\section{Results and discussion}

After adopting a prior cross-validation on the data, probabilistic neural network was conducted for modeling the discrete lithofacies, as distinct digits $[1,2, n]$, given the aforementioned well $\log$ interpretations. The learn and

Table 2 Head of the sampled training subset data for the well under study

\begin{tabular}{|c|c|c|c|c|c|}
\hline & Depth & Sw & PhiN & Vsh & Lithofacies \\
\hline 301 & 3098.60 & 0.17 & 0.14 & 16.93 & sa \\
\hline 200 & 3083.20 & 0.05 & 0.20 & 5.15 & $\mathrm{sa}$ \\
\hline 456 & 3122.22 & 0.47 & 0.04 & 47.31 & shsa \\
\hline 490 & 3127.40 & 0.10 & 0.14 & 10.17 & sa \\
\hline 2 & 3053.03 & 0.04 & 0.22 & 4.10 & $\mathrm{sa}$ \\
\hline 457 & 3122.37 & 0.56 & 0.03 & 55.77 & shsa \\
\hline
\end{tabular}


Table 3 Head of the sampled testing subset data for the well under study

\begin{tabular}{|c|c|c|c|c|c|}
\hline & Depth & Sw & PhiN & Vsh & Lithofacies \\
\hline 316 & 3100.88 & 0.04 & 0.21 & 4.22 & sa \\
\hline 411 & 3115.36 & 1.00 & 0.00 & 100.00 & sh \\
\hline 146 & 3074.97 & 0.35 & 0.04 & 35.46 & shsa \\
\hline 592 & 3142.95 & 0.95 & 0.00 & 63.43 & sh \\
\hline 182 & 3080.46 & 0.07 & 0.20 & 6.98 & sa \\
\hline 616 & 3146.60 & 0.11 & 0.20 & 10.15 & sa \\
\hline
\end{tabular}

smooth functions in pnn $R$ package produce the observed and guessed discrete lithofacies distribution. The total correct percent (classification success rate) of the classified lithofacies was automatically calculated after computing the count of success and fail points. The resulted success rate in this study was $95.81 \%$, and this rate is accurate enough for the PNN algorithm to be considered for further facies prediction. The comparison between the observed and predicted lithofacies is shown in Fig. 4.

In core permeability modeling, the predicted discrete lithofacies distribution of sand, shaly sand, and shale was included into the generalized boosted regression model (GBM) as a fifth predictor in addition to well depth, neutron porosity, shale volume, and water saturation. The $\mathrm{gbm}$ function, in the $\mathrm{gbm} R$ package, requires defining gaussian distribution for permeability as a loss function. It also requires determining the number of iterations and the $k$ fold for the built-in cross-validation. To ensure more accurate modeling, the number of maximum iterations was set to 50,000 with twofold for the cross-validation; while the optimal number of iterations is automatically specified by gbm.perf function. Through $\mathrm{gbm}$ function implementation, the relative influence is calculated to show the most influential predictors on the response (core permeability).

The lithofacies distribution has the most effect on the core permeability modeling because of the distinct permeability distribution given each facies of sand, shaly sand, and shale. The water saturation and depth are more
Fig. 4 Box-plots of the observed and predicted discrete lithofacies by the PNN algorithm
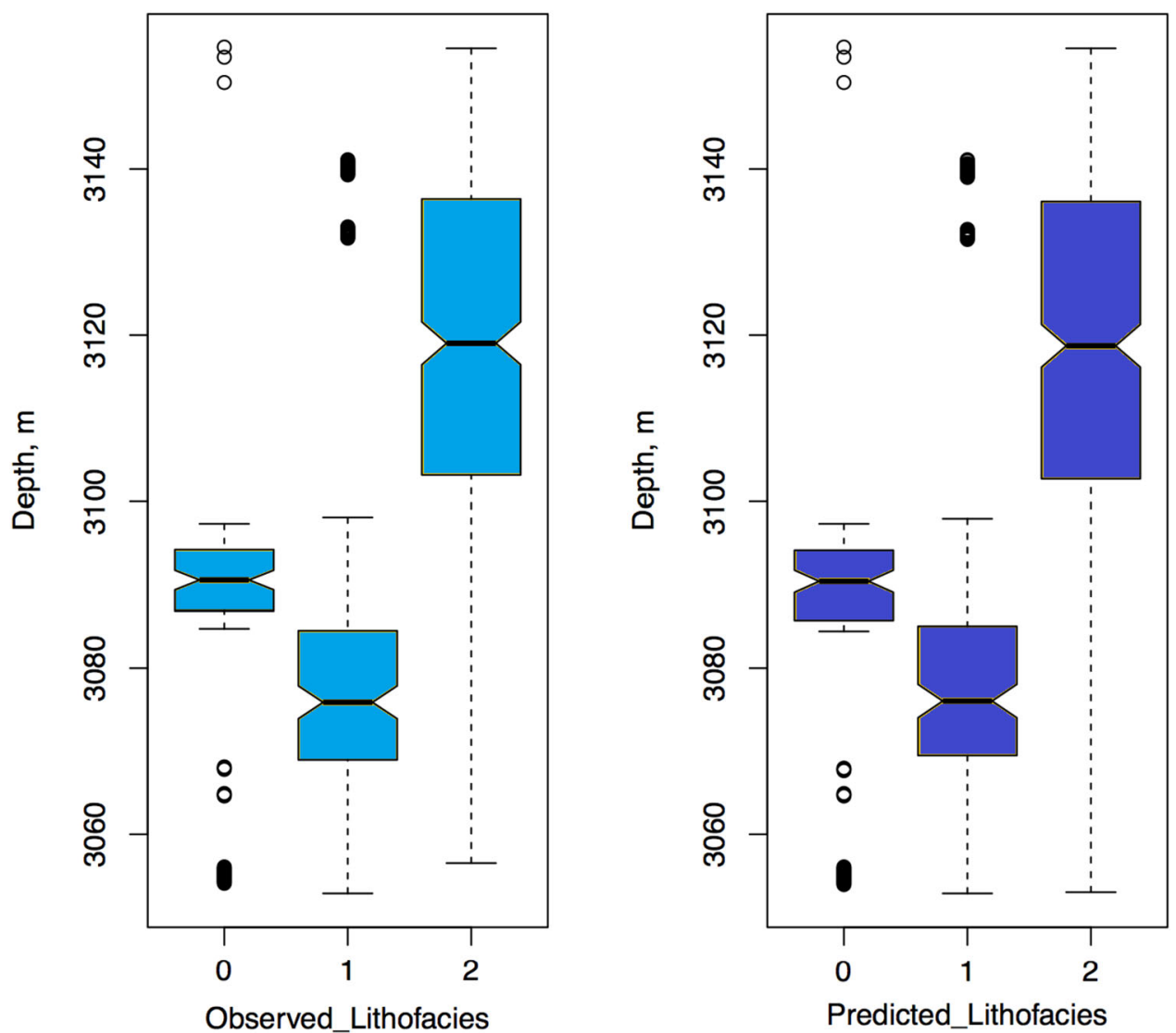
influential than neutron porosity and shale volume. However, the shale volume is less influencing than water saturation because both have the same data behavior as both reflect the same rock and fluid characteristics. Also, they represent a multicollinearity and one of them should be removed from the regression model. Depth parameter also has a significant effect because it controls the locations of high and low permeability ranges given the lithofacies within the reservoir thickness, as shown in Fig. 3 where the sand distribution located at the top depth intervals, shale located at the middle, and shaly sand of medium ranges located at the bottom depth intervals. Figure 5 illustrates the relative influence of the predictors in the GBM-core permeability modeling.

The maximum number of iterations was set in for the $\mathrm{gbm}$ function to be 50,000 . However, the resulted number that led to obtain the best fit and least square-error loss is 49,995 , which was automatically indicated by the gbm.perf function in the R $\mathrm{gbm}$ package, as shown in Figure 6. The gbm.perf function estimates the optimal number of boosting iterations for a $\mathrm{gbm}$ object and optionally plots various performance measures (Ridgeway 2017). In Fig. 6, the black and green lines refer to the training and testing Bernoulli deviances, respectively. The iteration (tree) selected for prediction, indicated by the vertical blue dashed line, is the tree that minimizes the testing error on the cross-validation folds (Ridgeway 2017).

The GBM algorithm obtained the most accurate permeability modeling and prediction. The accuracy is identified from the excellent matching between the observed and predicted core permeability, as shown in the scatterplot in Fig. 7. The computed root-mean-square prediction error (RMSPE) was 28.43, and the adjusted R-square was 0.9953. In Fig. 7, both the predicted and observed permeability were located on the same linear trend without misfit.

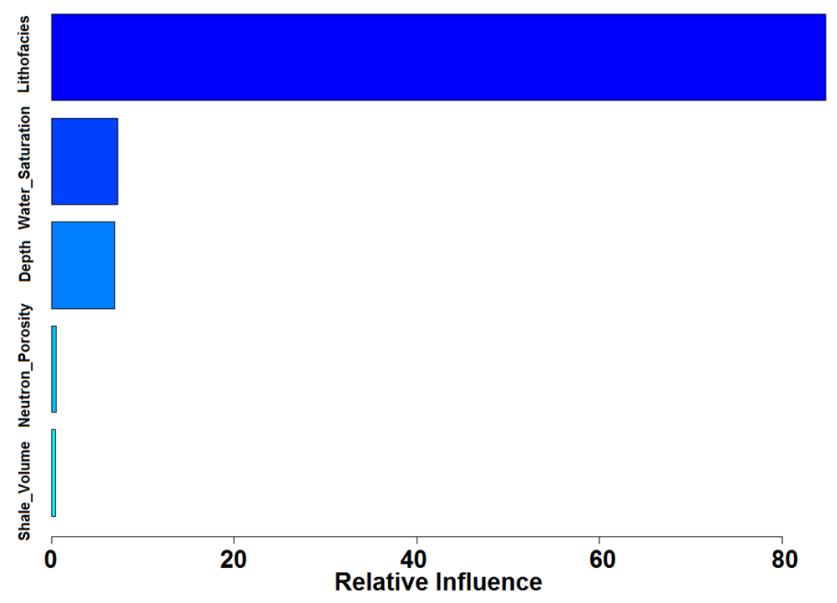

Fig. 5 Relative influence of the predictors in the GBM-core permeability modeling

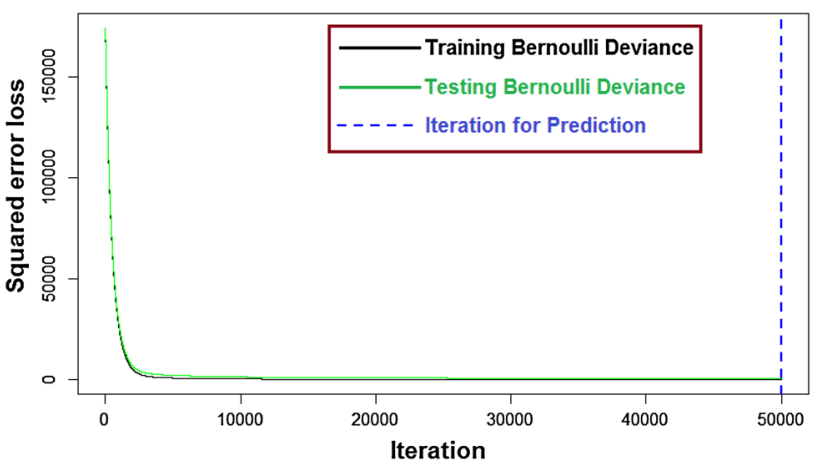

Fig. 6 Optimal number of iterations in the GBM algorithm indicated by the vertical blue dashed line, while the black and green lines refer to the training and testing Bernoulli deviances, respectively

This fact can be likewise seen in Fig. 8 that show the matching between vertical distributions of predicted and observed permeability given the well depth. The value of adjusted R-square is 0.9953 , and it reflects how sure that the given dataset can be represented by the $\mathrm{gbm}$ approach and how negligible the variance can be explained by this model as well.

\section{Further validation}

To show the effectiveness of the generalized boosted regression in core permeability modeling, the same procedure was repeated considering the conventional multiple linear regression (MLR). The same dataset was sampled and split for training and testing subsets through the crossvalidation. The computed adjusted R-square and RMSPE by the MLR were 0.9551 and 88.42 , respectively. There was a significant difference between the GBM and MLR predictions as the RMSPE for GBM is much less than in MLR. That reflects the least mismatch between the observed and predicted core permeability by the GBM. Figure 9 illustrates the scatterplot between the MLR-predicted and observed core permeability. Figure 10 depicts the distribution matching between the predicted core permeability by MLR with the observed measurements for the entire reservoir depth. There is clear mismatch between the MLR-predicted and observed permeability for many depth intervals.

\section{Summary and conclusions}

In order to predict the lithofacies and core permeability at the noncored intervals in a reservoir with preserving its heterogeneity, a powerful workflow that includes lithofacies in the permeability modeling should be adopted. That workflow was implemented in this paper through

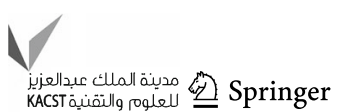


Fig. 7 Scatterplot of predicted and observed core permeability given the testing subset by GBM algorithm

Fig. 8 Matching between the entire vertical predicted and observed core permeability distributions by GBM algorithm
Adj.R-sq=0.9953 \& RMSPE $=28.43$
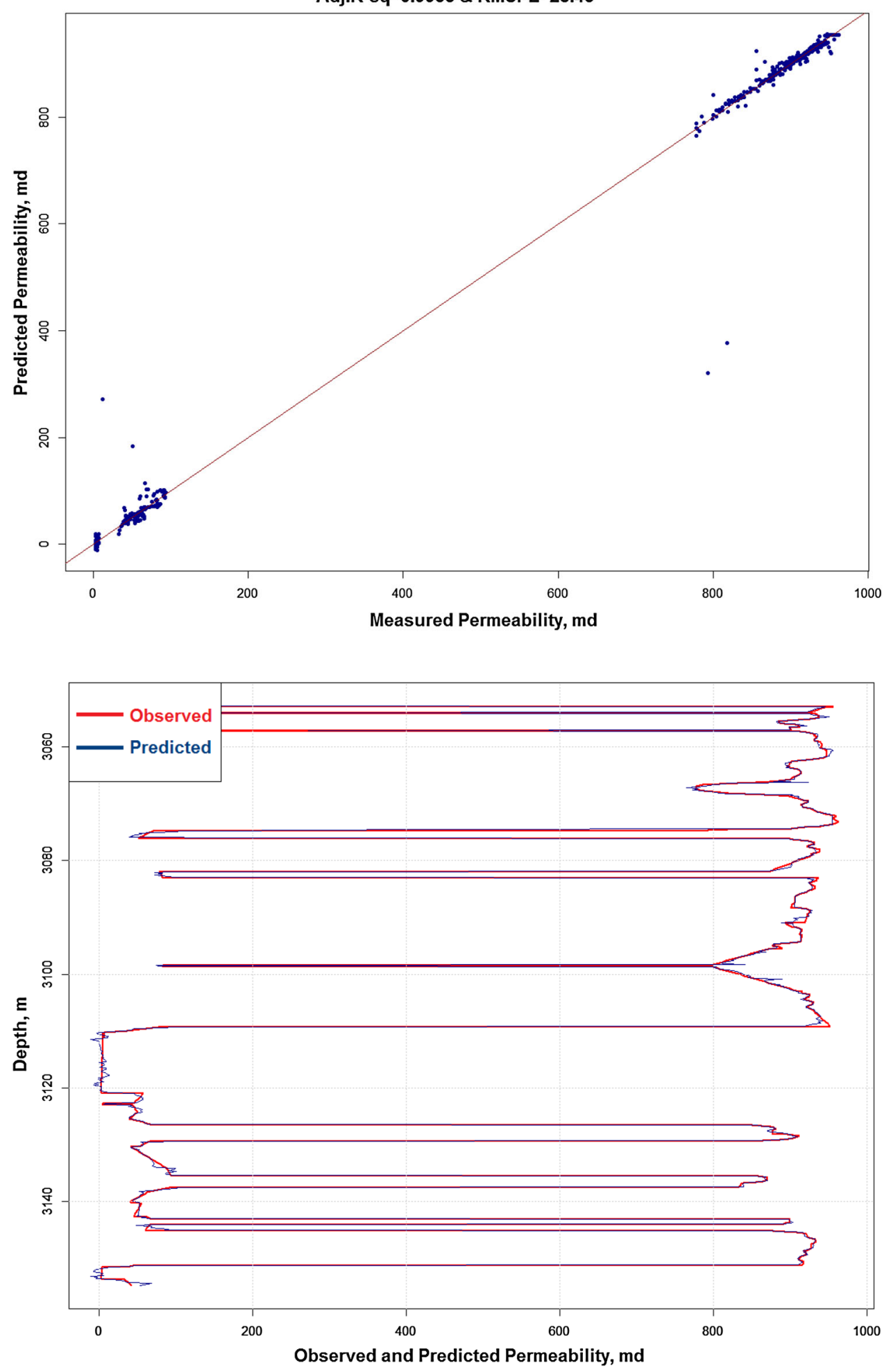

probabilistic neural networks (PNNs) for lithofacies classification and generalized boosted regression model (GBM) for permeability modeling. More specifically, the discrete core-measured lithofacies of sand, shaly sand, and shale were modeled as a function of the well log interpretations of neutron porosity, shale volume, and water saturation through the PNN algorithm. Then, the predicted discrete lithofacies distribution and the well log interpretations were included in the GBM model for the core permeability modeling. 
Fig. 9 Scatterplot of predicted and observed core permeability given the testing subset by MLR algorithm

Fig. 10 Matching between the entire vertical predicted and observed core permeability by MLR algorithm
Adj.R-sq=0.9551 \& RMSPE=88.42
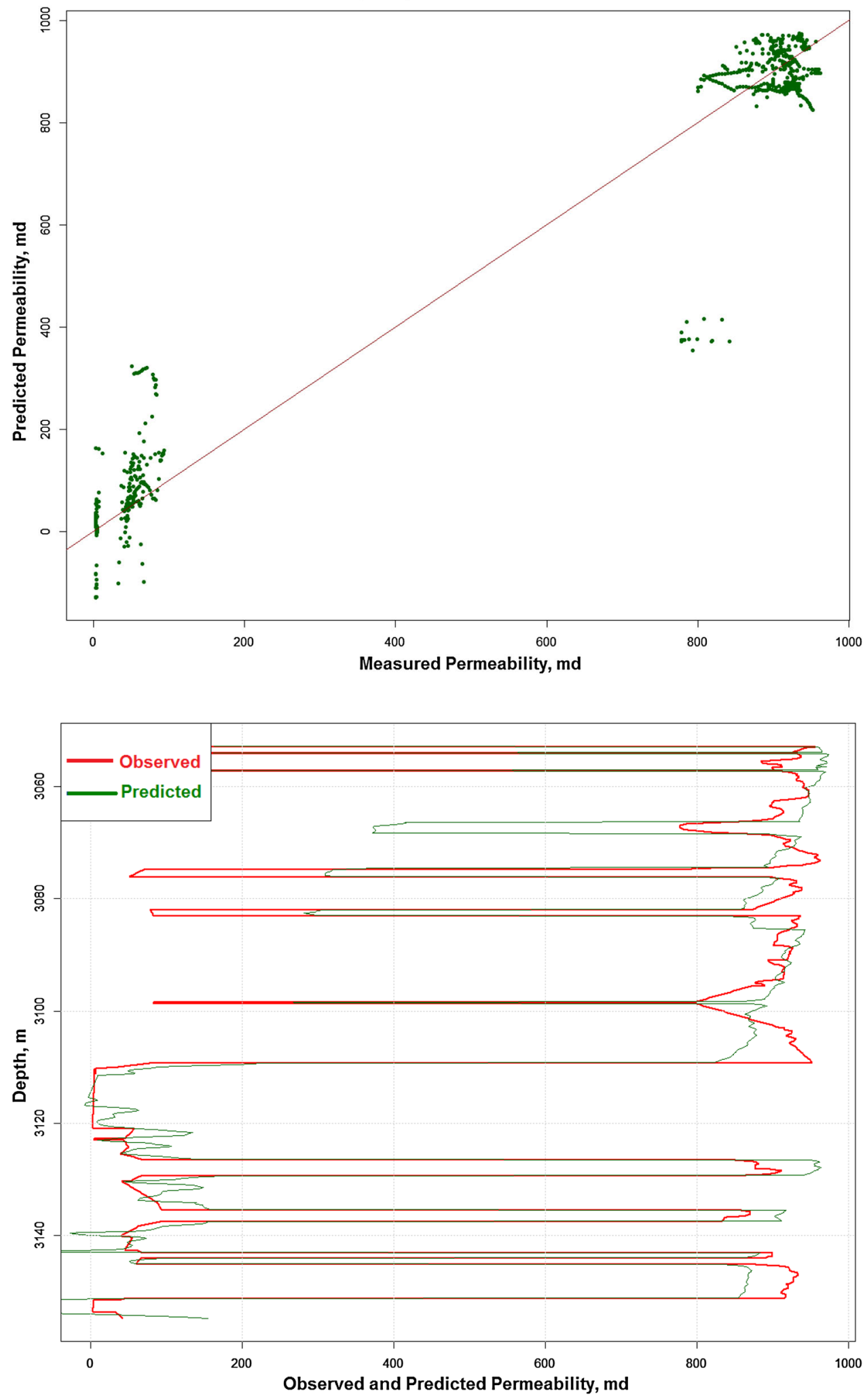

The PNN classification algorithm led to accurate facies classification as the total success rate exceeded $95 \%$. There was also an excellent matching between the predicted and observed discrete distributions of lithofacies. That reflects the ability of PNN algorithm to generate nonlinear relationship between the data from various sources and scales. 
The GBM algorithm created a nonlinear relationship, which is necessary for nonlinear geological systems, between the core permeability given the predictors of well $\log$ interpretations and lithofacies. The nonlinearity modeling resulted in the excellent matching between the observed and predicted core permeability for all depth intervals of the reservoir with a very small prediction error. Additionally, the efficiency of GBM results was validated by repeating the procedure of permeability modeling through the conventional multiple linear regression (MLR). The matching between the GBM-based predicted and observed permeability was much more accurate than the MLR as the root-mean-square prediction error was less and adjusted R-square was higher in GBM than in MLR.

To validate the results of the variously presented algorithms, the cross-validation was conducted prior to the permeability modeling by sampling and splitting the data into training and testing subsets. The modeling was adopted in the training subset, and prediction was then conducted given the testing part to make an external prediction from the same dataset and reduce the prediction uncertainty.

Finally, a precise prediction of rock facies leads to improve the well logging-permeability relationships and then obtain adequate permeability modeling with preserving reservoir heterogeneity. Additionally, integrating facies characterization into the permeability modeling results in accurately identifying the vertical and spatial facies as well as boosting the petrophysical property distribution for improved overall reservoir characterization.

Acknowledgements The author would like to present his thanks and appreciation to the Institute of International Education for granting him the Fulbright Science and Technology International Award that has funded the PhD Research at Louisiana State University.

Open Access This article is distributed under the terms of the Creative Commons Attribution 4.0 International License (http:// creativecommons.org/licenses/by/4.0/), which permits unrestricted use, distribution, and reproduction in any medium, provided you give appropriate credit to the original author(s) and the source, provide a link to the Creative Commons license, and indicate if changes were made.

\section{References}

Adoghe LI, Aniekwe OS, Nwosu C (2011) Improving electrofacies modeling using multivariate analysis techniques: a deepwater turbidite case study. In: Nigeria annual international conference and exhibition (30 July-3 August), Abuja, Nigeria. doi:10.2118/ 150776-MS

Al-Ameri TK, Al-Khafaji AJ, Zumberge J (2009) Petroleum system analysis of the Mishrif reservoir in the Ratawi, Zubair, North and South Rumaila oil fields, Southern Iraq. GeoArabia 4(4):91-103
Al-Ansari R (1993) The petroleum geology of the Upper sandstone member of the Zubair formation in the Rumaila South Oilfield. Ministry of Oil, Department of Reservoirs and Fields Development-Section of Production Studies.

Al-Anazi AF, Gates ID (2011) Support-vector regression for permeability prediction in a heterogeneous reservoir: a comparative study. SPE Reserv Eval Eng 13(03):485-495. doi:10.2118/ 126339-PA

Al-Mudhafar WJM (2014) Integrating Markov chains for Bayesian estimation of vertical facies sequences through linear discriminant analysis. In: European association of geoscientists and engineers. doi:10.3997/2214-4609.20141336

Al-Mudhafar WJ (2015a) Integrating component analysis and classification techniques for comparative prediction of continuous and discrete lithofacies distributions. In: Offshore technology conference, Houston, Texas. doi:10.4043/25806-MS

Al-Mudhafar WJ (2015b) Multinomial logistic regression for bayesian estimation of vertical facies modeling in heterogeneous sandstone reservoirs. In: Offshore technology conference Asia, Kuala Lumpur, Malaysia. doi:10.4043/24732-MS

Al-Mudhafar WJ (2017a) Integrating kernel support vector machines for efficient rock facies classification in the main pay of Zubair formation in South Rumaila oil field, Iraq. Model Earth Syst Environ 3:12. doi:10.1007/s40808-017-0277-0

Al-Mudhafar WJ (2017b) Geostatistical lithofacies modeling of the upper sandstone member/Zubair formation in South Rumaila oil field, Iraq. Arab J Geosci 10:153. doi:10.1007/s12517-017-2951-y

Al-Mudhafar W, Bondarenko MA (2015) Integrating K-means clustering analysis and generalized additive model for efficient reservoir characterization. In: 77th EAGE conference and exhibition incorporating SPE EUROPIC, Madrid, Spain. doi: $10.3997 / 2214-4609.201413024$

Al-Mudhafar WJ, Mohamed L (2015) Incorporating lithofacies classification and well logs into statistical learning algorithms for comparative multisource permeability modeling. In: SPE North Africa technical conference and exhibition, Cairo, Egypt. doi:10.2118/175776-MS

Al-Mudhafar WJ, Al-Khazraji AK (2016) Non-parametric adaptive regression spines for multisource permeability modeling in sandstone formation. In: Offshore technology conference Asia Kuala Lumpur, Malaysia. doi:10.4043/26431-MS

Avseth P, Mukerji T (2002) Seismic lithofacies classification from well logs using statistical rock physics. Petrophysics 43(02):70-81. doi:10.2118/170748-MS

Chasset (2015) Pierre-Olivier probabilistic neural-network. https:// cran.r-project.org/web/packages/pnn/pnn.pdf

Dahraj NUH, Bhutto AA (2014) Linear mathematical model developed using statistical methods to predict permeability from porosity. In: PAPG/SPE Pakistan section annual technical conference (24-27 November), Islamabad, Pakistan. doi:10. 2118/174716-MS

El Emary IMM, Srinivasan R (2008) On the application of various probabilistic neural networks in solving different pattern classification problems. World Appl Sci J 4(6):772-780

Freund Y, Schapire RE (1997) A decision-theoretic generalization of online learning and an application to boosting. J Comput Syst Sci 55(1):119-139

Friedman JH (2001) Greedy function approximation: a gradient boosting machine. Ann Stat 29(5):1189-1232

Friedman JH (2002) Stochastic gradient boosting. Comput Stat Data Anal 38(4):367-378

Lee SH, Datta-Gupta A (1999) Electrofacies characterization and permeability predictions in carbonate reservoirs: role of multivariate analysis and nonparametric regression. In: SPE annual 
technical conference and exhibition (3-6 October), Houston, Texas. doi:10.2118/56658-MS

Lee SH, Kharghoria A, Datta-Gupta A (2002) Electrofacies characterization and permeability predictions in complex reservoirs. SPE Reserv Eval Eng 5(03):237-248. doi:10.2118/78662-PA

Mao KZ, Tan KC, Ser W (2000) Probabilistic neural-network structure determination for pattern classification. IEEE Trans Neural Netw 11:10091016

Mohaghegh S, Balan B, Ameri S (1997) Permeability determination from well $\log$ data. SPE Form Eval 12(03):170-174. doi:10. 2118/30978-PA

Mohammed WJ, Al Jawad MS, Al-Shamaa DA (2010) Reservoir flow simulation study for a sector in main pay-south rumaila oil field. In: SPE Oil and Gas India Conference and Exhibition, Society of Petroleum Engineers, Mumbai

Nashawi IS, Malallah A (2009) Improved electrofacies characterization and permeability predictions in sandstone reservoirs using a data mining and expert system approach. Petrophysics 5(03):250-268

Natekin A, Knoll A (2013) Gradient boosting machines, a tutorial. Front Neurorobot 7:1-21

Rafik B, Kamel B (2016) Prediction of permeability and porosity from well $\log$ data using the nonparametric regression with multivariate analysis and neural network, Hassi RMel Field, Algeria, Egypt. J. Petrol. doi:10.1016/j.ejpe.2016.10.013

Ridgeway G (2017) Generalized boosted regression models. https:// cran.r-project.org/web/packages/gbm/gbm.pdf

Specht DF (1990) Probabilistic neural networks. Neural Netw 3(1): 109118
Tang H (2008) Improved carbonate reservoir facies classification using artificial neural network method. In: Canadian international petroleum conference (17-19 June), Calgary, Alberta, Canada. doi:10.2118/2008-122

Tang H, White C, Zeng X, Gani M, Bhattacharya J (2004) Comparison of multivariate statistical algorithms for wireline $\log$ facies classification. AAPG Ann Meet Abstr 88:13

Weston S, Calaway R (2015) Getting Started with doParallel and foreach. https://cran.r-project.org/web/packages/doParallel/vig nettes/gettingstartedParallel.pdf

Wong PM, Jian FX, Taggart IJ (1995) A critical comparison of neural networks and discriminant analysis in lithofacies, porosity and permeability predictions. J Pet Geol 18:191-206. doi:10.1111/j. 1747-5457.1995.tb00897.x

Xie J (2008) Improved permeability prediction using multivariate analysis methods. M.Sc. thesis. Texas A\&M University. http:// oaktrust.library.tamu.edu/bitstream/handle/1969.1/ETD-TAMU3223/XIE-THESIS.pdf? sequence $=1 \&$ isAllowed $=y$

$\mathrm{Xu} \mathrm{C}$, Heidari Z, Torres-Verdin C (2012) Rock classification in carbonate reservoirs based on static and dynamic petrophysical properties estimated from conventional well logs. In: SPE annual technical conference and exhibition (8-10 October), San Antonio, Texas, USA. doi:10.2118/159991-MS

Xue G, Datta-Gupta A, Valko P, Blasingame T (1997) Optimal transformations for multiple regression: application to permeability estimation from well logs. SPE Form Eval 12(02):85-94. doi:10.2118/35412-PA 